\title{
Alkali Chloride Cluster Ion Dissociation Examined by the Kinetic Method: Heterolytic Bond Dissociation Energies, Effective Temperatures, and Entropic Effects
}

\author{
Lianming Wu, Jeff W. Denault, and R. Graham Cooks \\ Department of Chemistry, Purdue University, West Lafayette, Indiana, USA \\ Lázló Drahos and Károly Vékey \\ Institute of Chemistry, Hungarian Academy of Sciences, Budapest, Hungary
}

\begin{abstract}
Branching ratios have been measured as a function of collision energy for the dissociation of mass-selected chloride-bound salt cluster ions, $\left[\mathrm{Rb}^{35}{ }^{35} \mathrm{Cl}-\mathrm{M}_{\mathrm{i}}\right]^{+}$, where $\mathrm{M}_{\mathrm{i}}=\mathrm{Na}, \mathrm{K}, \mathrm{Cs}$. The extended version of the kinetic method was used to determine the heterolytic bond dissociation energy (HBDE) of Rb-Cl. The measured value of $480.8 \pm 8.5 \mathrm{~kJ} / \mathrm{mol}$, obtained under single collision conditions, agrees with the HBDE value $(482.0 \pm 8.0 \mathrm{~kJ} / \mathrm{mol})$, calculated from a thermochemical cycle. The observed effective temperature of the collisionally activated salt clusters increases with laboratory-frame collision energy under both single- and multiplecollision conditions. Remarkably, the effective temperatures under multiple collision conditions are lower than those recorded under single-collision conditions at the same collision energy, a consequence of the inability of the triatomic ions to store significant amounts of internal energy. Laboratory-frame kinetic energy to internal energy transfer $(\mathrm{T} \rightarrow \mathrm{V})$ efficiencies range from 3.8 to $13.5 \%$. For a given cluster ion, the $\mathrm{T} \rightarrow \mathrm{V}$ efficiency decreases with increasing collision energy. Many features of the experimental results are accounted for using MassKinetics modeling (Drahos and Vékey, J. Mass Spectrom. 2001, 36, 237). (J Am Soc Mass Spectrom 2002, 13, 1388-1395) (C) 2002 American Society for Mass Spectrometry
\end{abstract}

$\mathrm{T}$ Thermochemical information has played a pivotal role in the development of ion/molecule chemistry [1]. Not only is this information useful in the interpretation and prediction of ionic reactivities and ion/molecule mechanisms, but the paucity of alternative sources of this information has made its acquisition an important application of ion/molecule reactions [2, 3]. Methods for determining absolute values of thermochemical quantities are rarely applicable, so relative values are typically measured by kinetic and equilibrium measurements on gas-phase ions. Theoretical calculations serve a special reference function [4]. Under appropriate conditions, the kinetics of the dissociation of molecular cluster ions can yield relative, but quantitative, thermochemical information on the constituent species [5]. The kinetic method, based on this concept, has been widely used for estimating thermochemical properties [5, 6]. Cluster ions bound via protons (eq 1), as well as other atomic or polyatomic anions or cations

Published online October 24, 2002

Address reprint requests to Dr. R. Graham Cooks, Chemistry Department, Purdue University, West Lafayette, IN 47907-1393, USA. E-mail: cooks@purdue.edu can be isolated and their dissociations followed in a tandem mass spectrometry experiment [7].

In eq $1, k_{1}$ and $k_{2}$ represent the rate constants for two

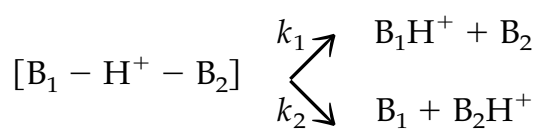

competitive dissociation channels of the proton-bound dimer to yield $\mathrm{B}_{1} \mathrm{H}^{+}$and $\mathrm{B}_{2} \mathrm{H}^{+}$, respectively. The ratio of rate constants, viz. the branching ratio of two fragment ion abundances, is related logarithmically to the gas-phase basicities of $B_{1}$ and $B_{2}$, in the standard form of the kinetic method:

$$
\ln \left(\frac{k_{1}}{k_{2}}\right)=\frac{\Delta(\Delta G)}{\mathrm{RT}_{\mathrm{eff}}}
$$

In eq 2, $\Delta(\Delta G)$ is the difference in gas-phase basicities of $B_{1}$ and $B_{2}, R$ is the gas constant, and $T_{\text {eff }}$ is the effective temperature (the parameter in the kinetic method which connects the degree of fragmentation of 
isolated ions to their mean internal energy [8]). Theoretical treatments of the kinetic method have been given [6]. Recently, various theoretical formulations of the statistical reaction rate theory (RRK, quantum-RRK, and RRKM), [9-11] as well as a finite heat bath theory (FHBT) simulation [12] have been applied in attempts to improve the theoretical basis of the kinetic method [8, 13, 14].

An important advance in the kinetic method, made by Fenselau and co-workers [15] and further probed by Wesdemiotis and his group [16, 17] was the recognition that differences in entropic effects in the competitive reactions need not cancel to allow thermochemical measurements to be made. Not only can enthalpy and free energy data be gleaned from this extended form of the kinetic method, but reaction entropy differences themselves can be estimated. While differences in the activation entropy change between the two competitive reactions need not be negligible in the Fenselau/Wesdemiotis treatment, they should be constant for a series of reference compounds. By acquiring abundance ratios at several collision energies and therefore, several effective temperatures, the difference in entropy change between the two dissociation channels can be measured by a double plotting method [16-21]. An improvement to this method that removes covariance of the slope and the intercept was suggested by Armentrout [14], who introduced appropriate statistical procedures and provided a simple means of analyzing the uncertainties in the thermodynamic quantities. In the systems studied so far, differences between Armentrout's and earlier data treatments do not lie in the quantitative results themselves but in the magnitudes of the errors associated with these values. It must also be noted that the use of the kinetic method for the estimation of relative reaction entropies is not universally accepted [22] although recent tests in which the extended form of the kinetic method is compared with results of a new entropy-corrected kinetic method [23] give encouraging results. The relative entropy term in the extended kinetic method has recently been discussed by Ervin in the context of a microcanonical analysis [22]. This author has argued that it may not be equal to the thermodynamic entropy difference for the two dissociation channels.

The HBDE is a fundamental thermochemical property, yet one that is relatively inaccessible for simple diatomic molecules AC (A is an anion and $\mathrm{C}$ is a cation). The HBDE value for a binary salt is to be contrasted with the better-known thermochemical quantity, the lattice energy. The kinetic method has been used to estimate HBDE values in two previous experiments, using fast-atom bombardment (FAB) [24] and electrospray ionization (ESI) [25] to generate the precursor cluster ions.

In the former study on ionic salt clusters, remarkably high effective temperature $\left(\mathrm{T}_{\text {eff }}\right)$ values were observed [24]. More recently, Cole and co-workers systematically examined halide-bound clusters $\left[\mathrm{M}_{1}-\mathrm{X}-\mathrm{M}_{2}\right]^{+}(\mathrm{X}=\mathrm{Cl}, \mathrm{I})$ and alkali-bound clusters $\left[\mathrm{X}_{1}-\mathrm{Na}-\mathrm{X}_{2}\right]^{-}$. In both positively and negatively-charged clusters, high $\mathrm{T}_{\text {eff }}$ values were also recorded. The extended version of the kinetic method was not used in these earlier investigations so this further investigation of triatomic salt clusters by the kinetic method in its extended form was undertaken in order to better understand this unusual chemical system. Special properties of triatomic salt clusters include:

1. The small number of degrees of freedom. This raises interesting questions regarding the applicability of statistical unimolecular kinetics.

2. The negligible kinetic shift. This means that all ions are expected to fragment immediately upon being activated to the dissociation threshold; the oscillator frequencies should have only a small influence on relative fragment ion abundances.

3. The strong ionic bonds. These are expected to make it difficult to provide enough internal energy in the activated ion to reach abundance ratios of the product ions that approach unity, even at high collision energy.

The goals of this study are (1) to extend our earlier preliminary study to cover a range of collision energies and pressures; (2) to further investigate the applicability of the kinetic method to measure HBDE under various conditions; (3) to estimate, if possible, reaction entropies using the extended version of the kinetic method; (4) to seek an understanding of energy partitioning $(\mathrm{T} \rightarrow \mathrm{V}$; collision energy to internal energy transfer efficiency) in salt clusters; and (5) to use MassKinetics modeling to elucidate the experimental findings and refine our understanding of the dissociation of small salt cluster ions.

\section{Experimental}

Experiments were performed using a Finnigan TSQ 700 triple quadrupole mass spectrometer (Thermo-Finnigan MAT, San José, CA). The manifold and ion source temperatures were held at 40 and $70{ }^{\circ} \mathrm{C}$, respectively. The FAB gun (Ion Tech, Teddington, UK) was operated at $5 \mathrm{kV}$ and $3 \mathrm{~mA}$ emission current to generate fast Ar atoms. The nominal manifold pressure was $6 \times 10^{-7}$ torr.

All chloride salts $(\mathrm{NaCl}, \mathrm{KCl}, \mathrm{RbCl}, \mathrm{CsCl})$ were purchased from Aldrich Chemical Co. (Milwaukee, WI) and used without purification. In pairwise fashion, two salts $(\mathrm{RbCl}$ and $\mathrm{NaCl}, \mathrm{KCl}$ or $\mathrm{CsCl}$, where $\mathrm{RbCl}$ is treated as the compound with unknown HBDE) were mixed with glycerol and placed on the stainless steel probe tip and bombarded with energetic argon atoms.

The mixed cluster ion $\left[\mathrm{M}-{ }^{35} \mathrm{Cl}-\mathrm{M}_{\mathrm{i}}\right]^{+}$generated in the ion source was mass-selected using the first quadrupole mass filter. Collisional activation of the selected cluster ion was achieved in the second rf-only quadrupole at various collision energies $(20,30$, and $50 \mathrm{eV}$, respectively) under either single-collision conditions (i.e., pri- 
Table 1. Calculated heterolytic bond dissociation energies for $\mathrm{NaCl}, \mathrm{KCl}$ and $\mathrm{CsCl}$ using a thermochemical cycle ${ }^{\mathrm{a}}$

\begin{tabular}{lccc}
\hline Salt $\mathrm{M}_{\mathrm{i}} \mathrm{Cl}$ & $\mathrm{HBDE}(\mathrm{kJ} / \mathrm{mol})$ & $\begin{array}{c}\text { Average HBDE }(\mathrm{HBDE}) \\
(\mathrm{NaCl}+\mathrm{KC} 1+\mathrm{CsCl})(\mathrm{kJ} / \mathrm{mol})\end{array}$ & $\begin{array}{c}\mathrm{HBDE}\left(\mathrm{M}_{\mathrm{i}}\right)-\mathrm{HBDE} \\
(\mathrm{kJ} / \mathrm{mol})\end{array}$ \\
\hline \hline $\mathrm{M}_{\mathrm{i}}=\mathrm{Na}$ & 559.0 & 512.1 & 46.9 \\
$\mathrm{M}_{\mathrm{i}}=\mathrm{K}$ & 502.9 & 512.1 & -9.20 \\
$\mathrm{M}_{\mathrm{i}}=\mathrm{Cs}$ & 474.5 & 512.1 & -37.6 \\
\hline
\end{tabular}

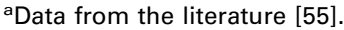

mary ion beam attenuated by less than $20 \%$ ) or multiple-collision condition (i.e., primary ion beam attenuated by more than $80 \%$ ) by varying the pressure of the Ar collision gas [26]. The product ion mass spectra were recorded by scanning the third quadrupole. All peak ratios were measured in triplicate and displayed relative standard deviations of less than $10 \%$. Mass-to-charge ratios are reported using the Thomson unit $(1 \mathrm{Th}=1 \mathrm{~m} / \mathrm{z})$ [27].

Calculations were performed using the MassKinetics Scientific (Ver. 1.2), which is a more powerful version of Masskinetics Demo (the latter available at http:/ / www. chemres.hu/ms/masskinetics). MassKinetics is a collection of methods for modeling mass spectrometric processes, discussed in detail recently [28]. It combines modeling of unimolecular reaction rates with consideration of energy exchange processes to calculate product ion abundances as the ions move through various parts of a mass spectrometer. In MassKinetics ions are characterized by their internal and kinetic energies. Essential features of the MassKinetics model are the use of internal (and, as necessary, kinetic) energy distributions and the use of probabilities to describe transitions between different states. Reaction rates are calculated based on transition state theory (TST) in its RiceRamsperger-Kassel-Marcus (RRKM) formulation [2931]. The kinetic and/or internal energies of ions in the gas phase may change due to (1) acceleration in electromagnetic fields, (2) radiative energy exchange (photon absorption and emission), (3) collisional energy exchange, and (4) energy partitioning during dissociation, each of which is taken into account. Amongst these factors, collisional energy exchange may be described using different collision models. Energy exchange processes and fragmentation take place in the same timeframe, and both are taken into account simultaneously using master-equation models [32]. While the mathematical description of these physical processes is quite complex, MassKinetics has the advantage that ion abundances can be calculated accurately using very few empirical (adjustable) parameters [8, 33]. The MassKinetics algorithm has been used to develop a (similarly named) PC-based software program. Calculations presented in this communication can be downloaded from the MassKinetics site, allowing further tests on this system to be performed by the interested reader. In MassKinetics calculations, vibrational frequencies of the reactant and product ions and of the transition states are required. The critical energies for the dissociations are also needed. To provide this information, quantum chemical calculations were performed using the Gaussian 98 package [34]. Because the relativistic effects in these heavy atoms ( $\mathrm{Rb}, \mathrm{Cs})$ are large [35], effective core potentials were used for the calculations. The structures of the molecular ions and of the fragments ions were fully optimized at the DFT(B3LYP) [36-38] level of theory with the SDD basis set [39]. The calculated frequencies were scaled using the value suggested before $(0.9806)$ [40, 41]. Vibrational frequencies were specified with an accuracy of $1 \mathrm{~cm}^{-1}$.

The unimolecular dissociations of these salt clusters are believed to go through loose transition states, with no substantial energy barrier [30]. In order to be able to find the exact geometries of the transitional states, Variational Transition State Theory (VTST) [42, 43] was applied to these systems. The vibrational frequencies were calculated along the reaction coordinates, using the same level of theory as above. The sum of states was calculated from the frequencies by direct state counting [44]. The transition state was located at a reaction coordinate that corresponds to the minimum in the sum of states. The detailed results of the VTST calculations are soon to be published (Sztáray, J.; Drahos, L.; Vékey, $\mathrm{K}$., unpublished). The critical energies of the dissociations were obtained from the total energies of the optimized species. An average collision cross section of $90 \AA^{2}$ was used for all ions, an approximation based on calculated radii of the ions and justified by the fact that the number of collisions is controlled by the pressure in these experiments.

\section{Results and Discussion}

\section{Applicability of the Kinetic Method to Thermochemical Determinations Using Small Ion- Bound Salt Clusters}

The difference in the heterolytic bond dissociation energy (HBDE) for $\mathrm{NaCl}$ and $\mathrm{CsCl}$ is calculated from literature thermochemical cycles (Table 1) as $84.5 \mathrm{~kJ} /$ mol $(0.86 \mathrm{eV})$. In order to directly measure relative HBDE values, branching ratios were measured for the dissociations of the cluster ions generated by mixing $\mathrm{RbCl}$ (chosen as the compound with unknown HBDE) and either $\mathrm{NaCl}, \mathrm{KCl}$, or $\mathrm{CsCl}$. Competitive dissociations of the triatomic cluster ions $\left[\mathrm{Rb}-{ }^{35} \mathrm{Cl}-\mathrm{Mi}\right]^{+}$where $\mathrm{M}_{\mathrm{i}}$ is either $\mathrm{Na}, \mathrm{K}$, or Cs, were examined in pairwise fashion. 


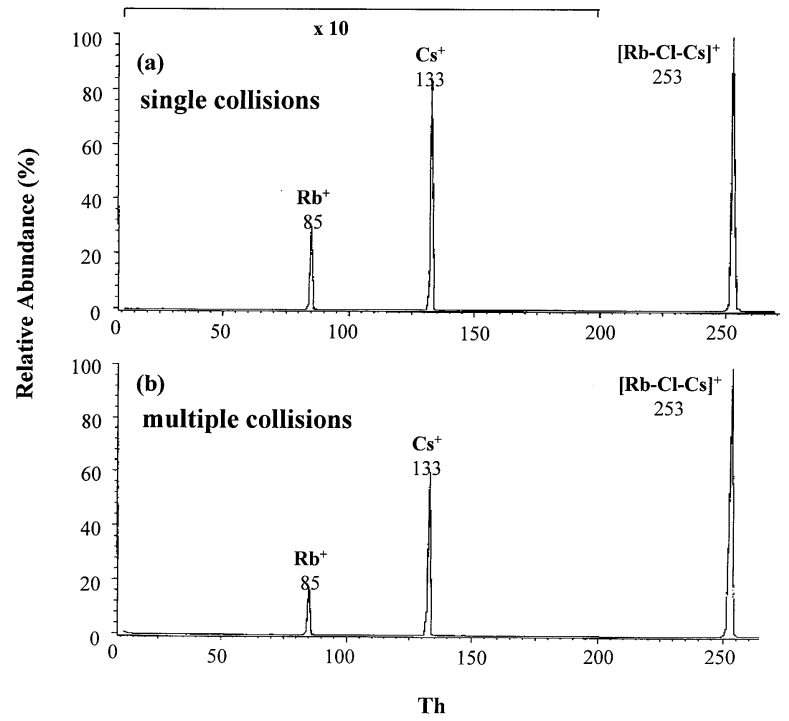

Figure 1. Product ion MS/MS spectrum of the mass-selected cluster ion $\left[\mathrm{Rb}-{ }^{35} \mathrm{Cl}-\mathrm{Cs}\right]^{+}$. Activation was achieved at $20 \mathrm{eV}$ lab collision energy under (a) single collision conditions and (b) multiple collision conditions.

Figure 1 shows a typical product ion mass spectrum, that of the mixed ionic cluster $\left[\mathrm{Rb}^{35}{ }^{35} \mathrm{Cl}-\mathrm{Cs}\right]^{+}$. The fragments at 85 and 133 Thomson correspond to the cations of $\mathrm{Rb}^{+}$and $\mathrm{Cs}^{+}$, respectively. Simple inspection of the ratios of fragment ion abundances (Figure 1) suggests that $\mathrm{RbCl}$ has a greater heterolytic bond dissociation energy (HBDE) than $\mathrm{CsCl}$. The same order was observed under both single (Figure 1a) and multiple (Figure $1 \mathrm{~b}$ ) collision conditions. This trend is consistent with the data obtained from independent thermochemical calculations, as shown in Table 1. In order to obtain quantitative information, it is necessary to consider the entropy requirements of the two competitive dissociations.

Relative reaction entropies of the two competitive fragmentations can arguably be equated to relative reaction entropies for heterolytic bond dissociation, i.e., for reactions of the type $\mathrm{RbCl} \rightarrow \mathrm{Rb}^{+}+\mathrm{Cl}^{-}$. To access these relative fragmentation entropies, branching ratios for dissociation of the triatomic clusters were recorded at different collision energies, corresponding to different effective temperatures (the mean internal energy of fragmenting ions, as recently suggested by Drahos and Vékey using MassKinetics modeling [8] and by Laskin and Futrell using finite heat bath theory [12]). Figure 2a shows that linear correlations exist when applying the kinetic method at 20,30,50 eV collision energies under single collision conditions. Under different conditions (various collision energies and multiple collision conditions), similar kinetic plots were obtained (not shown). From these data, effective temperatures, shown in Tables 2 and 3, can be extracted. In the extended form of the kinetic method the intercepts obtained from the energy-dependent kinetic plots are replotted versus the corresponding slopes to give straight lines. In these new
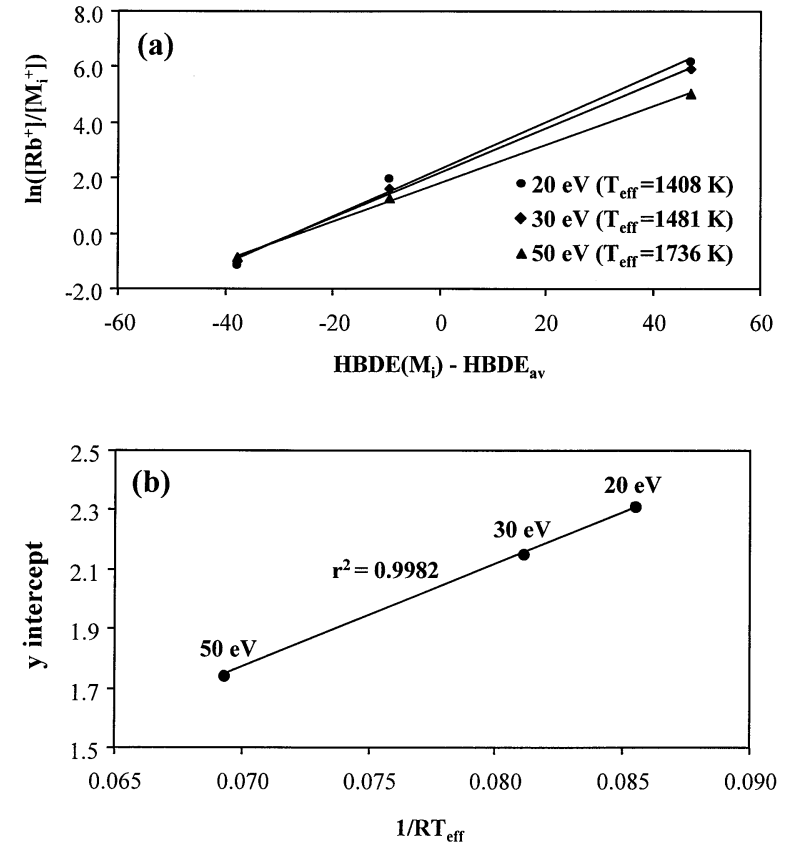

Figure 2. (a) Armentrout procedure for the determination of the $\mathrm{Rb}-\mathrm{Cl}$ heterolytic bond dissociation energy (HBDE) by plotting $\ln \left(\left[\mathrm{Rb}^{+}\right] /\left[\mathrm{M}_{\mathrm{i}}^{+}\right]\right)$versus $\left(\operatorname{HBDE}\left(\mathrm{M}_{\mathrm{i}}\right)-\mathrm{HBDE}_{\mathrm{av}}\right)$ where $\mathrm{M}_{\mathrm{i}}=\mathrm{Na}, \mathrm{K}$, Cs. Three collision energies were used, $20 \mathrm{eV}$ (filled circle, $\mathrm{r}^{2}=$ 0.9900), $30 \mathrm{eV}$ (filled diamond, $\mathrm{r}^{2}=0.9975$ ), and $50 \mathrm{eV}$ (filled triangle, $\left.r^{2}=0.9988\right)$, under single collision conditions. The branching ratio corresponding to each point is the average value of triplicate measurements. (b) Double plotting procedure of Armentrout for the determination of HBDE; plot of y intercept obtained from (a) versus $1 / \mathrm{RT}_{\text {eff }}$. Correlation coefficient $\left(\mathrm{r}^{2}\right)=$ 0.9982 .

plots, typified by Figure $2 b$, the slopes and intercepts correspond to the HBDE for $\mathrm{RbCl}$ and the difference in entropy change for the two competing dissociation channels of the salt clusters (Table 4). The experimentally measured HBDE for $\mathrm{RbCl}$ is $480.8 \pm 8.5 \mathrm{~kJ} / \mathrm{mol}$, as measured under single-collision conditions and evaluated by the Armentrout plotting procedure. This value is consistent with the HBDE value of $482.0 \pm 8.0 \mathrm{~kJ} / \mathrm{mol}$ calculated from the thermochemical cycle. The HBDE value obtained under multiple collision conditions is in agreement, within the experimental uncertainties (Table 4). The uncertainties in both the measured ion abundance ratios and the calculated values for HBDEs of the reference compounds lead to a combined estimated uncertainty of approximate $8.5 \mathrm{~kJ} / \mathrm{mol}$, indicating that the extended kinetic method provides HBDE values with a smaller estimated error than the simple kinetic method $(\sim 12 \mathrm{~kJ} / \mathrm{mol})$. The fact that entropy contributions are not negligible (Table 4) means that the use of the simple version of the kinetic method is not the best method in this case.

In the unimolecular-reaction based kinetic method as just implemented, the two competitive reaction rates depend on the thermochemical properties and on the (electronic, vibrational, and rotational) states of a massselected ion. The internal energy of such an isolated ion 
Table 2. Fragment ion abundance and kinetic method data under single-collision conditions ${ }^{\mathrm{a}}$ as a function of lab collision energy

In $\left(\left[\mathrm{Rb}^{+}\right] /\left[\mathrm{M}_{\mathrm{i}}^{+}\right]\right)$(survival yield $\left.{ }^{\mathrm{b}}\right)$

\begin{tabular}{|c|c|c|c|c|c|c|c|}
\hline $\begin{array}{l}\text { CID } \\
\mathrm{eV}\end{array}$ & $\mathrm{Na}$ & K & Cs & $\begin{array}{l}\text { Slope }^{c, d} \\
\left(1 / R T_{\text {eff }}\right)\end{array}$ & $y$ intercept ${ }^{c}$ & $y$ intercept ${ }^{d}$ & $T_{\text {eff }}^{c, d}(K)$ \\
\hline 20 & $6.18(0.922)$ & $1.95(0.920)$ & $-1.17(0.916)$ & 0.0854 & -41.936 & 2.317 & $1408 \pm 125$ \\
\hline 30 & $5.92(0.919)$ & $1.63(0.914)$ & $-1.01(0.912)$ & 0.0812 & -39.423 & 2.147 & $1481 \pm 139$ \\
\hline 50 & $5.02(0.916)$ & $1.29(0.912)$ & $-0.870(0.898)$ & 0.0693 & -33.554 & 1.751 & $1736 \pm 158$ \\
\hline
\end{tabular}

andicated CID collision gas argon pressure of $0.18 \mathrm{~m}$ Torr.

bDefined as the ratio of parent abundance to the total ion abundances after CID.

${ }^{c}$ Kinetic method plot of natural logarithm of the abundance ratio of the two monomeric fragments $\left(\ln \left[\mathrm{Rb}^{+}\right] /\left[\mathrm{M}_{\mathrm{i}}^{+}\right]\right)$versus $\mathrm{HBDE}\left(\mathrm{M}_{\mathrm{i}}\right)$.

${ }^{d}$ Kinetic method plot of natural logarithm of the abundance ratio of the two monomeric fragments $\left(\operatorname{In}\left[\mathrm{Rb}^{+}\right] /\left[\mathrm{M}_{\mathrm{i}}^{+}\right]\right)$versus $\left(\mathrm{HBDE}\left(\mathrm{M}_{\mathrm{i}}\right)-\mathrm{HBDE}_{\mathrm{av}}\right)$.

is statistically distributed amongst vibrations and internal rotations. It is obvious that small salt clusters (with only three atoms) are not ideally suitable to statistical treatment. However, in spite of this non-ideality, the kinetic method gives useful results that are consistent with those available by other means.

\section{Entropy Requirements of the Two Competitive Fragmenting Reactions of Salt Clusters}

In the kinetic method, the difference in entropy change in the two competitive reactions, rather than their absolute values are of interest [7]. If it is assumed that the dissociation of an ion-bound salt cluster ion has a loose dissociation transition state [45], the differences in the entropies of the two dissociation channels are mainly due to the vibrational entropy contributions. This is reasonable, since there are large differences in the frequencies of the dissociating bonds in these activated clusters. The measured average difference in the entropy change on dissociation of salt clusters is small $(2.3 \mathrm{~J} / \mathrm{mol} \cdot \mathrm{K}$ as shown in Table 4$)$, as expected if simple bond cleavages are involved, but not zero. Much larger entropy contributions are found in the dissociation of proton-bound peptide dimers, due to the intramolecular hydrogen bonding in these systems [15].

\section{Kinetic to Internal Energy Transfer $(T \rightarrow V)$ Efficiency}

Collisional processes depend on two main factors: The probability of a collision and the outcome of a single collision. The outcome of multiple collisions is determined by the combination of these two parameters. The probability of collision depends on the pressure of a collision gas, and the velocity-dependent collision cross-section. Kinetic (translational, T) to internal energy (vibrational, V) transfer controls the internal energy of the collision partners and determines the outcome of a collision event. The most important parameter influencing energy transfer in a collision event is the center-of-mass (com) collision energy, the maximum amount of kinetic energy that may be converted into internal energy in a collision in the course of completely inelastic scattering [46]. The greater the collision energy transfer, the higher the internal energy of the activated system, as indicated for example by the effective temperature measured from its unimolecular dissociation behavior.

These features are clearly illustrated in Figure 3 which shows results of MassKinetics modeling for the salt cluster $\left[\mathrm{Na}-{ }^{35} \mathrm{Cl}-\mathrm{Rb}\right]^{+}$. Note that the increase of effective temperature is nearly linear with the $\mathrm{T} \rightarrow \mathrm{V}$ conversion efficiency (Figure $3 b$ ) and the experimentally observed very high effective temperatures $(>1000$ K) which can be explained by the MassKinetics calculation. The greater the excess internal energy of the ions (above the critical energy), the more likely they are to dissociate, and hence the lower the survival yields, as shown in Figure 3a. Deactivation is not explicitly discussed here but is considered in MassKinetics and other treatments of low energy, multiple-collision CID [47]. Note also that the $\mathrm{T} \rightarrow \mathrm{V}$ energy transfer is not independently calculated in the MassKinetics program: the

Table 3. Fragment ion abundance and kinetic method data under multiple-collision conditions ${ }^{\mathrm{a}}$ as a function of lab collision energy

\begin{tabular}{|c|c|c|c|c|c|c|c|}
\hline \multirow[b]{2}{*}{$\begin{array}{l}\text { CID } \\
\mathrm{eV}\end{array}$} & \multicolumn{3}{|c|}{ In $\left(\left[\mathrm{Rb}^{+}\right] /\left[\mathrm{M}_{\mathrm{i}}^{+}\right]\right)$(survival yield ${ }^{\mathrm{b}}$ ) } & \multicolumn{4}{|c|}{$\begin{array}{c}\text { Kinetic method Plot using Fenselau }^{c} \text { or Armentrout }^{d} \\
\text { procedure }\end{array}$} \\
\hline & $\mathrm{Na}$ & $\mathrm{K}$ & Cs & $\begin{array}{l}\text { Slope } \\
\left(1 / R T_{\text {eff }}\right)\end{array}$ & $\mathrm{y}$ intercept $^{\mathrm{c}}$ & $y$ intercept $^{d}$ & $T_{\text {eff }}^{c, d}(K)$ \\
\hline 20 & $5.43(0.682)$ & $1.65(0.646)$ & $-0.991(0.466)$ & 0.107 & -51.964 & 3.053 & $1120 \pm 118$ \\
\hline 30 & $5.01(0.671)$ & $1.45(0.637)$ & $-0.961(0.433)$ & 0.103 & -49.797 & 2.883 & $1169 \pm 113$ \\
\hline 50 & $4.26(0.658)$ & $1.24(0.630)$ & $-0.831(0.414)$ & 0.0997 & -48.295 & 2.784 & $1205 \pm 121$ \\
\hline
\end{tabular}

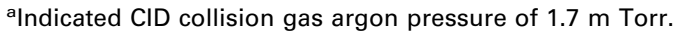

${ }^{b}$ Defined as the ratio of parent abundance to the total ion abundances after CID.

${ }^{c}$ Kinetic method plot of natural logarithm of the abundance ratio of the two monomeric fragments $\left(\operatorname{In}^{2}\left[\mathrm{Rb}^{+}\right] /\left[\mathrm{M}_{\mathrm{i}}^{+}\right]\right) \mathrm{versus}^{\mathrm{HBDE}}\left(\mathrm{M}_{\mathrm{i}}\right)$.

${ }^{d}$ Kinetic method plot of natural logarithm of the abundance ratio of the two monomeric fragments $\left(\ln \left[\operatorname{Rb}^{+}\right] /\left[\mathrm{M}_{\mathrm{i}}{ }^{+}\right]\right) \mathrm{versus}\left(\mathrm{HBDE}\left(\mathrm{M}_{\mathrm{i}}\right)-\mathrm{HBDE}_{\text {av }}\right)$. 
Table 4. Summary of $\mathrm{HBDE}$ and $\Delta(\Delta \mathrm{S})$ for $\mathrm{Rb}-\mathrm{Cl}$ measured using the kinetic method

\begin{tabular}{lccrr}
\hline & \multicolumn{2}{c}{$\operatorname{HBDE}(\mathrm{Rb}-\mathrm{Cl})(\mathrm{kJ} / \mathrm{mol})$} & \multicolumn{2}{c}{$\Delta(\Delta \mathrm{S})(\mathrm{JK} / \mathrm{mol})^{\mathrm{a}}$} \\
\cline { 2 - 5 } CID & $\begin{array}{c}\text { Fenselau } \\
\text { collision }\end{array}$ & $\begin{array}{c}\text { Armentrout } \\
\text { Procedure }^{\mathrm{b}}\end{array}$ & $\begin{array}{c}\text { Fenselau } \\
\text { Procedure }^{\mathrm{b}}\end{array}$ & $\begin{array}{c}\text { Armentrout } \\
\text { Procedure }^{\mathrm{c}}\end{array}$ \\
\hline \hline Single & $481.7 \pm 8.6$ & $480.8 \pm 8.5$ & $2.3 \pm 1.9$ & $3.0 \pm 2.2$ \\
Multiple & $476.8 \pm 8.7$ & $477.0 \pm 8.4$ & $6.2 \pm 3.6$ & $6.0 \pm 3.7$ \\
\hline
\end{tabular}

aValue reflects entropy difference for the two competitive dissociation reactions during CID.

${ }^{b}$ Kinetic method plot of natural logarithm of the abundance ratio of the two monomeric fragments $\left(\operatorname{In}\left[\mathrm{Rb}^{+}\right] /\left[\mathrm{M}_{\mathrm{i}}{ }^{+}\right]\right)$versus $\mathrm{HBDE}\left(\mathrm{M}_{\mathrm{i}}\right) . \%{ }^{\mathrm{d}} \mathrm{Kinetic}$ method plot of natural logarithm of the abundance ratio of the two monomeric fragments $\left(\ln \left[\operatorname{Rb}^{+}\right] /\left[\mathrm{M}_{\mathrm{i}}^{+}\right]\right)$versus $\left(\mathrm{HBDE}\left(\mathrm{M}_{\mathrm{i}}\right)-\mathrm{HBDE}_{\mathrm{av}}\right)$.

values are obtained by fitting the experimental and calculated dissociation behavior using a partially inelastic model that assumes the internal energy uptake to depend on the kinetic energy and the $\mathrm{T} \rightarrow \mathrm{V}$ efficiency, but not on the initial internal energy.

The $\mathrm{T} \rightarrow \mathrm{V}$ conversion efficiency varies for different systems [48]. In the alkali halide salt clusters, lab collision energy to internal energy transfer $(\mathrm{T} \rightarrow \mathrm{V})$ efficiencies under single collision conditions range from 3.8 to $13.5 \%$ (Table 5). It was found that at the same collision energy, the lab $\mathrm{T} \rightarrow \mathrm{V}$ transfer efficiency increases with decreasing critical energy for the dissociation of activated cluster ions from $\left[\mathrm{Na}^{-}{ }^{35} \mathrm{Cl}-\mathrm{Rb}\right]^{+}$to $\left[\mathrm{K}-{ }^{35} \mathrm{Cl}-\mathrm{Rb}\right]^{+}$to $\left[\mathrm{Cs}^{-}{ }^{35} \mathrm{Cl}-\mathrm{Rb}\right]^{+}$. For the same cluster ion, the $\mathrm{T} \rightarrow \mathrm{V}$ transfer efficiency decreases as the laboratory frame collision energy increases (i.e., at higher lab collision energies, a smaller fraction of collision energy is converted into internal energy), this result is similar to that of earlier studies of collision energy transfer at high energy (keV) [49], although in several low collision energy studies, partitioning is constant with increasing internal energy [10, 49-52].

The magnitude of the energy partitioning is not yet understood in detail and is probably dependent on the mechanism of collisional activation [10, 49-52]. For example, the energy partitioning observed in this system is much smaller than the average $41 \%$ com conversion efficiency for nitrogen colliding with protonated
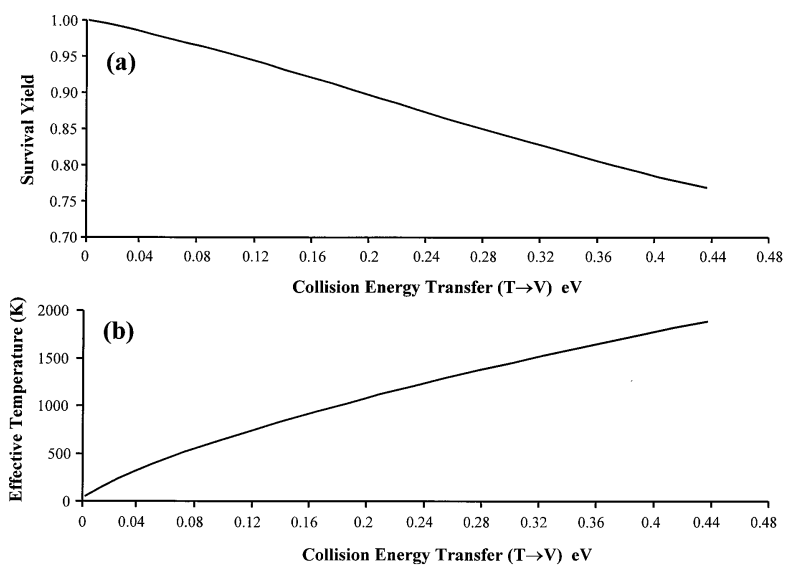

Figure 3. MassKinetics modeling for the salt cluster $\left[\mathrm{Na}-{ }^{35} \mathrm{Cl}-\right.$ $\mathrm{Rb}]^{+}$, showing (a) large decrease in survival yield and (b) large increase in the effective temperature $\mathrm{T}_{\text {eff }}$ with increasing energy transfer under single collision conditions. bradykinin (a peptide with 444 internal degrees of freedom). On the other hand, the energy partitioning is much smaller in pentapeptide dimers [53] and much more similar to the values seen in this study in the proton-bound dimers of small molecules [54].

\section{Effective Temperature Decrease Under Multiple Collision Conditions}

The effective temperature measures the mean excess internal energy of the fragmenting activated complex, i.e., of the cluster ion. Three facts, (1) the strong ionic bonds (high binding energy), (2) the small number of oscillators, (3) the energy transfer probabilities combine to cause salt clusters to have extremely high effective temperatures. Some of these values are shown in Tables 2 and 3. As expected, the survival yield, which is defined as the ratio of the parent ion abundance before CID and after CID, decreases rapidly under multiple collision conditions (compare Figure 1a and b). This means that the more highly activated ions, with internal energy well above the dissociation threshold, fragment more readily under multiple collision conditions.

By contrast to expectation based on the behavior of ions with large number of degrees of freedom [52], the experimentally measured effective temperature $T_{\text {eff }}$ under multiple collision conditions (Table 3 ) is lower than that obtained under single collision conditions (Table 2). Normally, more collisions should result in ions acquiring more internal energy, resulting in the higher effective temperatures [52], although collisional relaxation effects under multiple collision conditions [47] complicate this picture. In the simple salt clusters under study, however, the kinetic shift is negligible (only four vibrators), so internal energy can be stored in the ions only up to the critical energy, above which the ion dissociates very rapidly. This removes the cluster ion and causes single collisions to give rise to higher internal energies than multiple collisions (compare the fragment ion abundance ratios in Figure 1). Based on this argument, the effective temperature is observed to decrease with increasing collision gas pressure. It is also interesting to point out that the effective temperatures increases more slowly with increasing collision energies (from 20, 30, to $50 \mathrm{eV}$ ) under multiple collision conditions (Table 3) than under single collision conditions 
Table 5. $\mathrm{T} \rightarrow \mathrm{V}$ transfer efficiency for different salt clusters at lab collision energies of 20,30 , and $50 \mathrm{eV}$ under single-collision conditions $^{\mathrm{a}}$

\begin{tabular}{|c|c|c|c|c|c|c|}
\hline \multirow[b]{2}{*}{$\begin{array}{l}\text { Lab } \\
\text { collision } \\
\text { energy } \\
(\mathrm{eV})\end{array}$} & \multicolumn{2}{|c|}{$\mathrm{Na}-{ }^{35} \mathrm{Cl}-\mathrm{Rb}$} & \multicolumn{2}{|c|}{$\mathrm{K}-{ }^{35} \mathrm{Cl}-\mathrm{Rb}$} & \multicolumn{2}{|c|}{$\mathrm{Cs}^{-35} \mathrm{Cl}-\mathrm{Rb}$} \\
\hline & $\begin{array}{c}\text { com } \\
\text { collision } \\
\text { energy } \\
(\mathrm{eV})\end{array}$ & $\begin{array}{c}\mathrm{T} \rightarrow \mathrm{V} \\
\text { transfer } \\
\text { efficiency } \\
(\%)\end{array}$ & $\begin{array}{c}\text { com } \\
\text { collision } \\
\text { energy } \\
(\mathrm{eV})\end{array}$ & $\begin{array}{c}\mathrm{T} \rightarrow \mathrm{V} \\
\text { transfer } \\
\text { efficiency } \\
(\%)\end{array}$ & $\begin{array}{c}\text { com } \\
\text { collision } \\
\text { energy } \\
(\mathrm{eV})\end{array}$ & $\begin{array}{c}\mathrm{T} \rightarrow \mathrm{V} \\
\text { transfer } \\
\text { efficiency } \\
(\%)\end{array}$ \\
\hline 20 & 4.5 & 6.8 & 4.0 & 11 & 2.7 & 14 \\
\hline 30 & 6.7 & 4.9 & 6.9 & 9.2 & 4.0 & 11 \\
\hline 50 & 11 & 3.8 & 10 & 7.7 & 5.2 & 8.0 \\
\hline
\end{tabular}

${ }^{a}$ Calculated using the experimental data and MassKinetics, see text.

(Table 2), which might be due to the greater kinetic energy loss during multiple collisions.

This qualitative argument is supported by MassKinetics calculations as illustrated in Figure 4. The survival yield (Figure 4a) decreases significantly with increasing collision gas (Ar) pressures from 0.18 mTorr (ca. 1.05 collisions, single collision conditions) to 1.7 mTorr (ca. 10 collisions, multiple collision conditions). The effective temperatures also decrease modestly (Figure $4 \mathrm{~b}$ ), which is consistent with the experimental results. These results lead to the prediction that within the statistical framework, higher collision gas pressures should result in lower effective temperatures in systems with very few degrees of freedom.

\section{Conclusions}

This study provides further insights into the applicability of the kinetic method to the estimation of thermochemical quantities and the applicability of the derived effective temperature value in studies of energy partitioning. The high effective temperatures of these systems are confirmed by both experimental results and
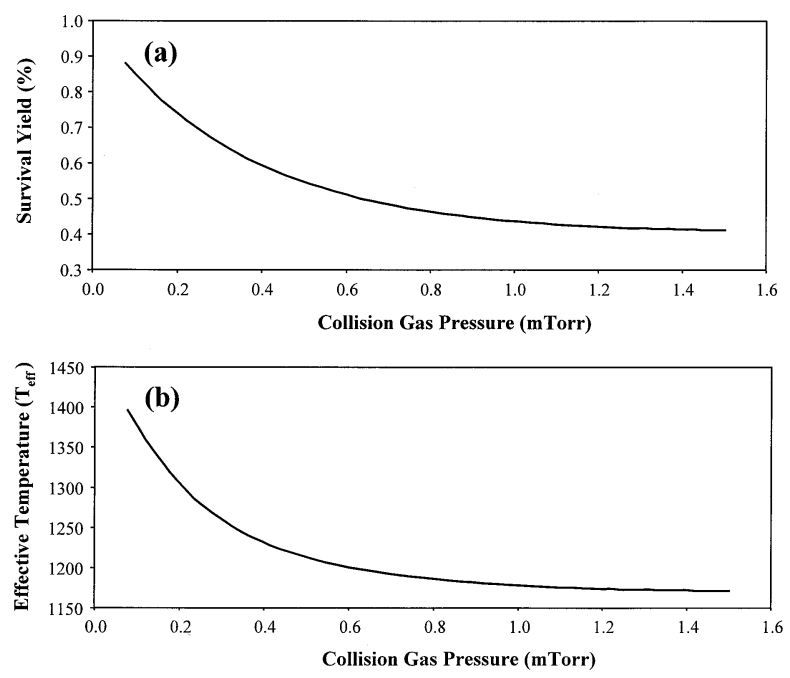

Figure 4. MassKinetics modeling for the salt cluster $\left[\mathrm{Na}-{ }^{35} \mathrm{Cl}-\right.$ $\mathrm{Rb}]^{+}$, showing collision gas (Ar) pressure effects on (a) survival yields of the parent ion after CID and (b) the effective temperature $\mathrm{T}_{\text {eff }}$ theoretical calculations, and are readily explained as a result of the small number of degrees of freedom into which a given amount of excess energy can be distributed. The effective temperature decreases with increasing numbers of collisions due to the increasingly rapid dissociation of the more highly excited ions. The lack of delayed dissociation means that multiple collisions do not build up internal energy in the activated ion as occurs in systems with larger numbers of degrees of freedom. This result, which contrasts strongly with that seen in most organic ions, was first predicted by the MassKinetics calculations and then shown experimentally. By combining the kinetic method results for effective temperature with MassKinetics calculations, one can derive internal energies of the activated cluster ions and hence laboratory frame kinetic energy to internal energy transfer $(T \rightarrow V)$ efficiency could be estimated. These data show that for a given cluster ion, the $\mathrm{T} \rightarrow \mathrm{V}$ efficiency decreases with increasing collision energy. This behavior is similar to that seen in the case of high energy $(\mathrm{keV})$ collisions, but contrasts with the available data on low energy collisions. Differences in the sizes of the systems make any further analysis difficult and suggest that the behavior of larger salt clusters should be studied. In spite of non-ideality of salt clusters based on the statistical application, good agreement between in the HBDE values obtained from the experimental measurement and from the thermochemical cycle calculations suggest that the kinetic method is useful to estimate HBDEs in these cases.

\section{Acknowledgments}

This work is supported by the U.S. Department of Energy, Office of Basic Sciences (Contract DE FG02-94ER14470). The authors are indebted to Judit Sztaray for quantum chemical calculations.

\section{References}

1. Franklin, J. L. Benchmark Papers in Physical Chemistry and Chemical Physics, No. 3: Ion-Molecule Reactions, Part. 1: Kinetics and Dynamics. Hutchinson and Ross, Inc.: Stroudsburg, 1979.

2. Lias, S. G.; Ausloos, P. J. Am. Chem. Soc. 1977, 99, 4831-4833.

3. Gal, J.-F.; Maria, P.-C.; Raczynska, E. D. J. Mass Spectrom. 2001, $36,699-716$. 
4. Alcamí, M.; Mó, O.; Yáñez, M. Mass Spectrom. Rev. 2001, 20, 195-245.

5. Cooks, R. G.; Kruger, T. L. J. Am. Chem. Soc. 1977, 99, 1279-1281.

6. Cooks, R. G.; Patrick, J. S.; Kotiaho, T.; McLuckey, S. A. Mass Spectrom. Rev. 1994, 13, 287-339.

7. Cooks, R. G.; Wong, P. S. H. Acc. Chem. Res. 1998, 31, 379-386.

8. Drahos, L.; Vékey, K. J. Mass Spectrom. 1999, 34, 79-84.

9. Craig, S. L.; Zhong, M.; Choo, B.; Brauman, J. I. J. Phys. Chem. A. 1997, 101, 5379.

10. Campbell, S.; Marzluff, E. M.; Rodgers, M. T.; Beauchamp, J. L.; Rempe, M. E.; Schwinck, K. F.; Lichtenberger, D. L. J. Am. Chem. Soc. 1994, 116, 5257-5264.

11. Ervin, K. M. Int. J. Mass Spectrom. 2000, 195/196, 271-284.

12. Laskin, J.; Futrell, J. H. J. Phys. Chem. A 2000, 104, 8829-8837.

13. Cooks, R. G.; Koskinen, J. T.; Thomas, P. D. J. Mass Spectrom. 1999, 34, 85-92.

14. Armentrout, P. B. J. Mass Spectrom. 1999, 34, 74-78.

15. Cheng, X. H.; Wu, Z. C.; Fenselau, C. J. Am. Chem. Soc. 1993, $115,4844-4848$.

16. Cerda, B. A.; Hoyau, S.; Ohanessian, G.; Wesdemiotis, C. J. Am. Chem. Soc. 1998, 120, 2437-2448.

17. Cerda, B. A.; Wesdemiotis, C. J. Am. Chem. Soc. 1996, 118, 11884-11892.

18. Lardin, H. A.; Squires, R. R.; Wenthold, P. G. J. Mass Spectrom. 2001, 36, 607-615.

19. Wenthold, P. G. J. Am. Soc. Mass Spectrom. 2000, 11, 601-605.

20. Kuntz, A. F.; Boynton, A. W.; David, G. A.; Colyer, K. E.; Poutsma, J. C. J. Am. Soc. Mass Spectrom. 2002, 13, 72-81.

21. Pommerening, C. A.; Bachrach, S. M.; Sunderlin, L. S. J. Am. Soc. Mass Spectrom. 1999, 10, 856-861.

22. Ervin, K. M. J. Am. Soc. Mass Spectrom. 2002, 13, 435-452.

23. Zheng, X.; Cooks, R. G. J. Phys. Chem. A, unpublished.

24. Chen, G.; Cooks, R. G. J. Mass Spectrom. 1997, 32, 1258-1261.

25. Wang, G.; Cole, R. B. J. Electron Spectrosc. Relat. Phenom. 2000, 108, 153-162.

26. Holmes, J. L. Org. Mass Spectrom. 1985, 20, 169-183.

27. Cooks, R. G.; Rockwood, A. L. Rapid Commun. Mass Spectrom. 1991, 5, 93.

28. Drahos, L.; Vékey, K. J. Mass Spectrom. 2001, 36, 237-263.

29. Steinfeld, J.; Francisco, J.; Hase, W. Chemical Kinetics and Dynamics. Prentice-Hall: New Jersey, 1989, 308-393.

30. Baer, T.; Hase, W. L. Unimolecular Reaction Dynamics. Oxford University Press: New York, 1996, 171-282.

31. Robinson, P. J.; Holbrook, K. A. Unimolecular Reactions. John Wiley and Sons Ltd.: Bristol, 1972, 64-184.
32. Oppenheim, I.; Shuler, K. E.; Weiss, G. H. Stochastic Processes in Chemical Physic: The Master Equation. M.I.T. Press: Cambridge, 1977.

33. Thomas, P. D.; Cooks, R. G.; Vékey, K.; Drahos, L. J. Phys. Chem. A 2000, 104, 1359-1361.

34. Frisch, M. J.; Trucks, G. W.; Schlegel, H. B.; Scuseria, G. E.; Robb, M. A.; Cheeseman, J. R.; Zakrzewski, V. G.; Montgomery, J. J. A.; Stratmann, R. E.; Burant, J. C.; Dapprich, S.; Millam, J. M.; Daniels, A. D.; Kudin, K. N.; Strain, M. C.; Farkas, O.; Tomasi, J.; Barone, V.; Cossi, M.; Cammi, R.; Mennucci, B.; Pomelli, C.; Adamo, C.; Clifford, S.; Ochterski, J. Petersson, G. A.; Ayala, P. Y.; Cui, Q. Gaussian 98 (Revision A). Gaussian Inc.: Pittsburgh, 1998.

35. Balasubramanian, K. Relativistic Effects in Chemistry, Part A, B. Wiley: New York, 1997.

36. Becke, A. D. Phys. Rev. A: Gen. Phys. 1988, 38, 3098-3100.

37. Becke, A. D. J. Chem. Phys. 1992, 97, 9173-9177.

38. Lee, C.; Yang, W.; Parr, R. G. Phys. Rev. B: Condens. Matter 1988, 37, 785-789.

39. Dunning, J. T. H.; Hay, P. J. In Modern Theoretical Chemistry; Schaefer, H. F., Ed.; Plenum: New York, 1976.

40. Rauhut, G.; Pulay, P. J. Phys. Chem. 1995, 99, 3093-3100.

41. Scott, A. P.; Radom, L. J. Phys. Chem. 1996, 100, 16502-16513.

42. Miller, W. H. J. Phys. Chem. 1983, 87, 21-22.

43. Pechukas, P. Ann. Rev. Phys. Chem. 1981, 32, 159-177.

44. Beyer, T.; Swinehart, D. R. ACM Commun. 1973, 16, 379-380.

45. Wigner, E. J. Chem. Phys. 1937, 5, 720-725.

46. Cooks, R. G. Collision Spectroscopy. Plenum Press: New York, 1978.

47. Wolfgang, R. P.; Li, H.; Cooks, R. G. Int. J. Mass Spectrom., unpublished.

48. Chen, G.; Cooks, R. G.; Bunk, D. M.; Welch, M. J.; Christie, J. R. Int. J. Mass Spectrom. 1999, 185/186/187, 75-90.

49. Kenttamaa, H. I.; Cooks, R. G. Int. J. Mass Spectrom. Ion Processes 1985, 52, 165-174.

50. Vékey, K.; Brenton, A. G.; Beynon, J. H. Int. J. Mass Spectrom. Ion Processes 1986, 70, 277-300.

51. Lee, S. H.; Kim, M. S.; Beynon, J. H. Int. J. Mass Spectrom. Ion Processes 1987, 75, 83-89.

52. McLuckey, S. A.; Cooks, R. G.; Fulford, J. E. Int. J. Mass Spectrom. 1983, 52, 165-174.

53. Marzluff, E. M.; Campbell, S.; Rodgers, M. T.; Beauchamp, J. L. J. Am. Chem. Soc. 1994, 116, 6947-6948.

54. Augusti, R.; Zheng, X.; Noll, R. J.; Cooks, R. G. J. Phys. Chem. $A$, to be published.

55. Lide, D. R. CRC Handbook of Chemistry and Physics; 75thed. CRC ress: Ann Arbor, 1995. 